\title{
RECONHECIMENTO SEDIMENTOLÓGICO DO ESTUÁRIO DO ITANAÍ-AÇU (SC)
}

\author{
WALDIR LOPES PONÇANO* e ANTONIO FERNANDO GIMENEZ* *
}

\begin{abstract}
Some sedimentological characteristics of the Itajaí-Açu estuary, in the Brazilian Southern coast, have been established through bottom and water samples collected in 1982 and 1983. Bottom samples representative of mean minimum fluvial discharge consist mainly of fine sediments, whereas those representative of mean maximum fluvial discharge and of a flooding event are basically sands. Water sample contents in salts and suspended matter show a salt-wedge pattern during high water, and a two-layer flow with vertical mixing pattern during low water, both for spring tides, under conditions of mean minimum fluvial discharge.
\end{abstract}

INTRODUÇÃO A porção terminal do Rio Itajaí-Açu constitui o principal estuário do Estado de Santa Catarina. Em seu interior encontra-se implantado o porto de Itajaí, que, juntamente com o porto de São Francisco do Sul, atende às demandas do Estado de Santa Catarina, predominando movimentação de granéis em São Francisco do Sul e de carga geral em Itajaí. Neste estuário, procedeu-se a um estudo sedimentológico visando caracterizar seus sedimentos de superfície de fundo sob condições de vazões fluviais máximas e mínimas. Adicionalmente, realizou-se estudo de distribuição de material em suspensão e de salinidade, sob condições de descarga fluvial mínima.

A área estudada situa-se em região de clima tropical temperado subquente superúmido, com precipitações médias anuais entre 1.250 e $1.500 \mathrm{~mm}$,com trimestre mais chuvoso em janeiro-fevereiro-março e menos chuvoso no inverno, e, secundariamente, no outono (Nimer 1977). As marés, na região do estuário do Itajaí-Açu, têm amplitudes máximas pouco inferiores a $1,4 \mathrm{~m}$ (Vargas 1983).

$\mathrm{O}$ estuário do Itajaí-Açu desenvolve-se em planície costeira relativamente estreita, entre morros de rochas cristalinas. A parte mais interior dessa planície apresenta terraços fluviais e marinhos enquanto que sua porção litorânea é essencialmente constituída de sucessivas linhas de antigas praias, configurando um lençol de areias regressivas, que, segundo Martin \& Suguio (1986), seriam holocênicas, mais jovens que um evento transgressivo ocorrido há cerca de 5.100 anos B.P.

Comparação de carta de fins do século passado com cartas náuticas atuais mostra que o trecho final do estuário do Itajaí-Açu teve suas características naturais profundamente alteradas. Assim, o estuário terminava em um braço de meandro com desembocadura para norte, feição que foi truncada por duas extensas linhas de molhes levemente convergentes. Sua construção terminou em 1952, quando criou-se então uma nova saída artificial, para o estuário voltada para E-NE (Fig. 1).

Além da conformação original do estuário, os recortes da costa na região do Itajaí-Açu caracterizam-se por enseadas que apresentam concavidades em suas porções a sul e crescimento de faixas sedimentares a norte. Estas feições são indi-
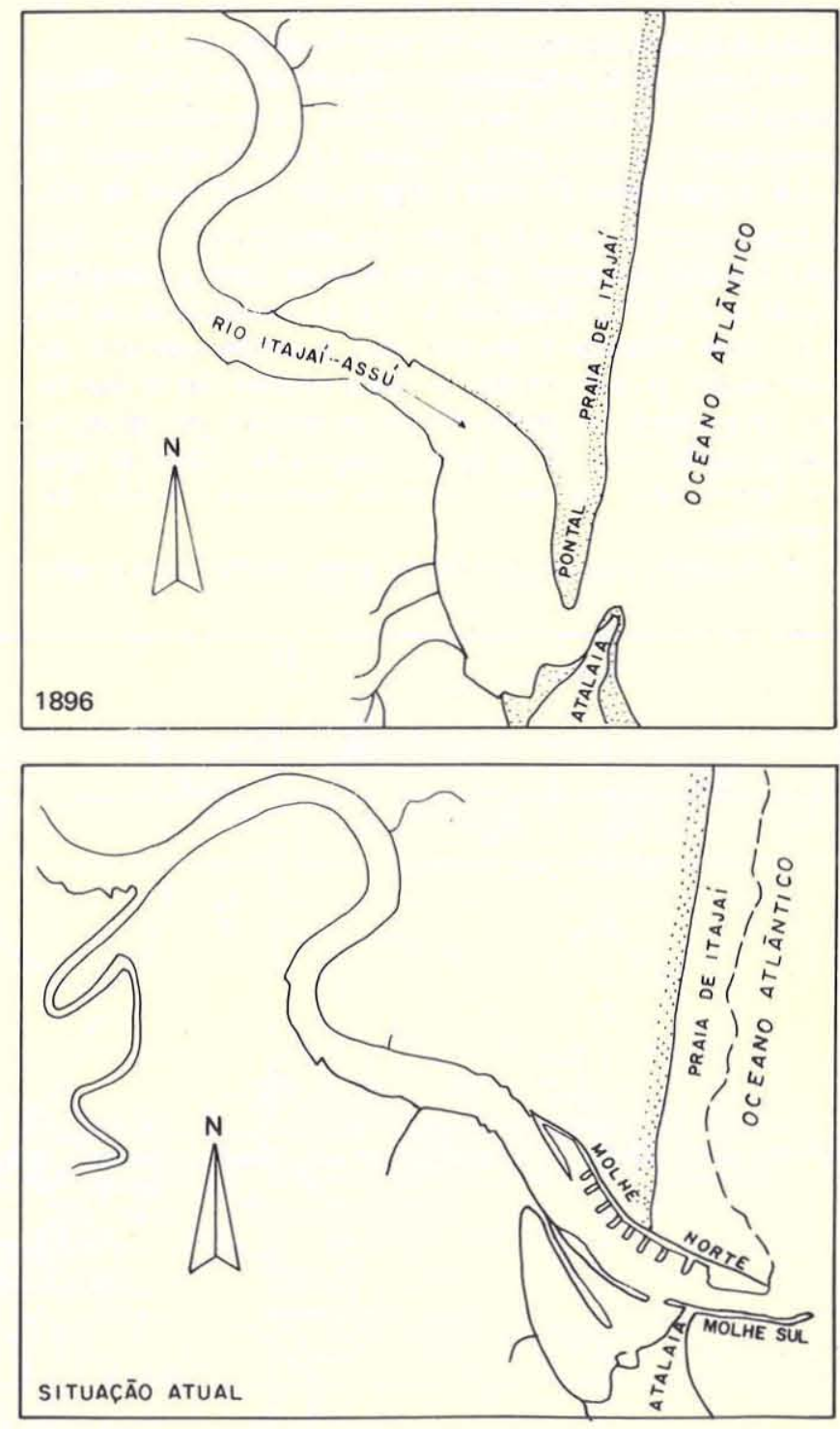

Figura 1 - Configuração do estuário do Itajai-Açu em 1896 e atualmente (segundo Vargas 1983)

* Instituto de Pesquisas Tecnológicas do Estado de São Paulo - IPT, Divisão de Minas e Geologia Aplicada. Cidade Universitária, Caixa Postal 7141, CEP 01000, São Paulo, SP, Brasil. Instituto de Geociências e Ciências Exatas, Universidade Estadual Paulista Júlio de Mesquita Filho, Campus de Rio Claro, CEP 13500, Rio Claro, SP Brasil

** Instituto de Pesquisas Tecnológicas do Estado de São Paulo - IPT, Divisão de Minas e Geologia Aplicada. Cidade Universitária, Caixa Postal 7141, CEP 01000, São Paulo, SP, Brasil 
cativas de transporte litorâneo predominante no sentido sul - norte, segundo critérios estabelecidos por Silvester (1969, 1974).

MATERIAIS E MÉTODOS A coleta de amostras, segundo as estações da figura 2, foi efetuada, no interior do estuário, com a utilização de barco especialmente adaptado a essa finalidade, fora da barra, foi usado o barco da praticagem local. As estações foram localizadas por meio de acidentes topográficos com auxílio de bússola, telêmetro e sextante, tendo-se por base cartas náuticas da Diretoria de Hidrografia e Navegação (DNH) e da Administração do Porto de Itajaí. Os sedimentos de superfície de fundo foram coletados com amostrador de mandíbula do tipo Van Veen; as amostras de água foram coletadas com garrafas de Van Door de 3 litros de capacidade, nas estofas de preamar e baixa-mar de sizígia, de 5 a 6 de outubro de 1983, estendendo-se cada amostragem entre 30 minutos antes e 30 minutos após os horários de referências dessas marés.

As amostras de sedimentos de superfície de fundo foram submetidas a análises granulométricas convencionais, com peneiramento a seco para a fração areia, em intervalos de $1 / 2 \phi$, e pipetagem de siltes e argilas, em intervalos de $1 \phi$. A granulometria dos sedimentos em suspensão foi analisada pelo Coulter Counter, que, de acordo com a literatura (Swift et al. 1972, Walker et al. 1974), constitui-se no método mais eficiente e preciso para o estabelecimento da distribuição granulométrica de material fino. Os teores totais de material em suspensão foram obtidos por pesagem com precisão de $\pm 10^{-4} \mathrm{~g}$, após filtragem de 1 litro de água em filtros Sartorius de $47 \mathrm{~mm}$ de diâmetro e $0,45 \mu$ de porosidade.

A descrição das características granulométricas dos sedi- mentos de superfície de fundo foi feita pelas fórmulas de Folk \& Ward (1957) e de classes texturais, segundo o diagrama de Shepard (1954 apud Suguio 1973).

A salinidade das amostras de água foi determinada por mediçőes em condutivímetro CM2A-Toa Electronics Ltd. Os valores de salinidade, apresentados em partes por milhão (ppm), são referidos aos equivalentes de $\mathrm{NaCl}$ a $25^{\circ} \mathrm{C}$.

Imagens de satélite, fotos aéreas, cartas náuticas e cartas topográficas foram usadas subsidiariamente na caracterização de movimentação de sedimentos e da morfologia costeira.

VAZÃo FLUVIAL E AMOSTRAGEM Levando em conta que os sedimentos da superfície de fundo representam uma resultante da dinâmica sedimentar, incluindo aí os fatores ligados à circulação das águas (Kutner 1976, Ponçano 1976), deve-se ponderar os resultados obtidos na caracterização faciológica em função de uma relação básica entre descarga fluvial e penetração da água do mar. Em decorrência, buscou-se, inicialmente, caracterizar o regime do rio. Além do reconhecimento, para o Itajaí-Açu, de período genericamente referido pela Portobrás como "águas altas", de julho a outubro, e "águas baixas", de dezembro a maio, não identificou-se nenhum trabalho que melhor o caracterizasse do ponto de vista hidrológico. Dados de vazão do Itajaí-Açu e do Itajaí-Mirim, referentes a uma série de 44 anos, de 1935 a 1978 , permitiram calcular, para a estação de Indaial, médias mensais de vazão bem como seus desvios-padrões (Fig. 3). Adicionalmente, calculou-se o coeficiente de variação dado pela razão entre desvio-padrão e média: quanto mais aquele se aproxima da unidade menos as médias são representativas.

0 Itajaí-Açu apresenta dois máximos e dois mínimos

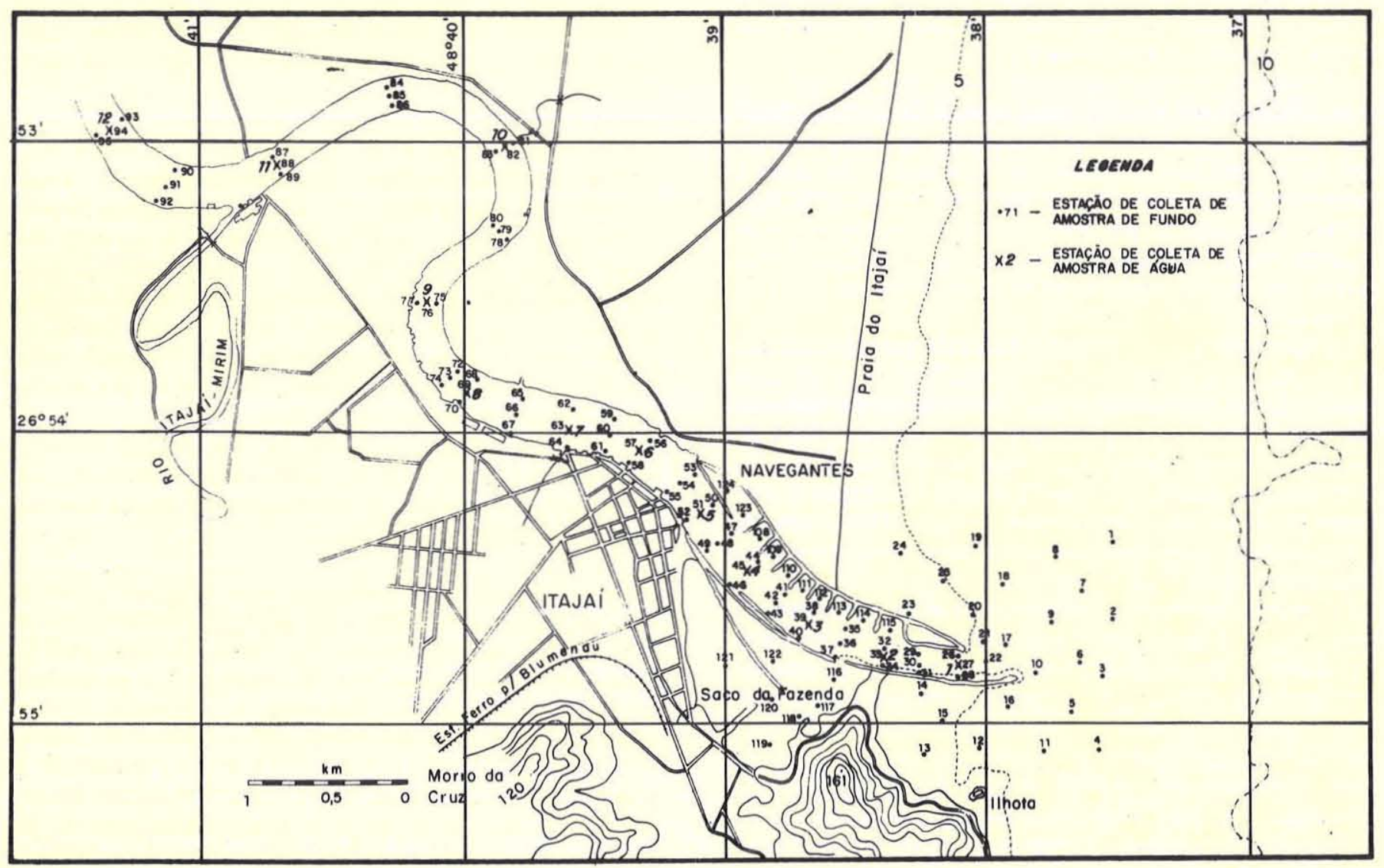

Figura 2 - Estações de coleta de amostras 
anuais de vazão. Os desvios-padrões das médias mensais são elevados aproximando-se da média no mês de agosto. Isto mostra um regime em que a uma certa regularidade sazonal impōem-se episódios de grandes descargas de primavera, responsáveis, provavelmente, pelo máximo assinalado entre setembro e outubro.

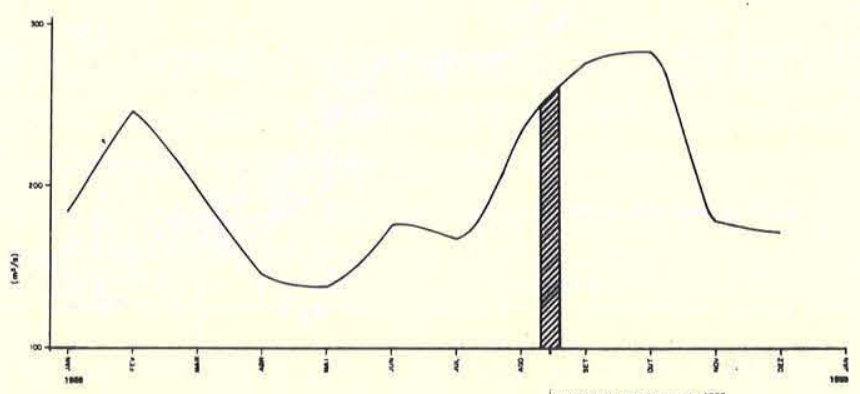$$
\text { g }
$$

Figura 3 - Vazão média mensal do Itajai-Açu na estação de Indaial, entre 1935 e 1978

A partir desses dados, esperava-se que a amostragem efetuada na primeira campanha de sedimentos de superfície de fundo estivesse situada em período de cheia do rio, quando, estatisticamente, a vazão do rio teria superado a marca das médias do máximo secundário, que ocorrem em fevereiro. No entanto, dadas as variações observadas nas médias mensais, especialmente no mês de agosto, a assertiva feita anteriormente teve de ser tomada com ressalvas. O significado da amostragem de 1982 só pôde ser analisado de modo mais real após a obtenção dos dados específicos referentes a 1982 já em 1983 (Fig. 4).

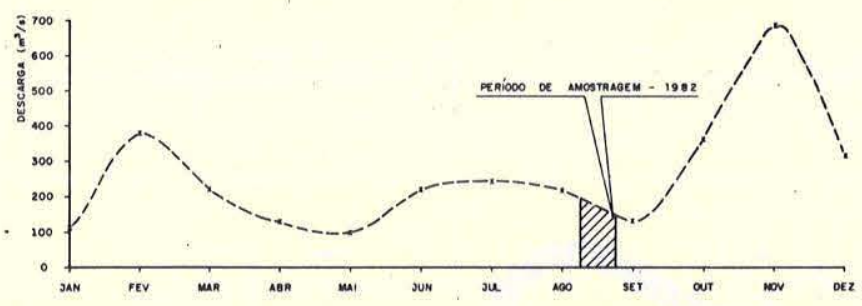

Figura 4 - Vazão do Itajai-Açu na estação de Indaial, em 1982

Uma revisão e uma avaliação qualitativa dos dados de vazão do Itajaí-Açu, realizadas em 1983 no 2.0 Distrito do DNAEE em Curitiba, foram fortemente sugestivas de que se possa provavelmente vir a definir dois comportamentos bá. sicos para o rio: no primeiro, decorrente de períodos de pluviosidade moderada, a distribuição de vazão seguiria aproximadamente o padrão da curva média da figura 3 , e no segundo, decorrente de anos excepcionalmente chuvosos, ocorreriam máximas de inverno, sempre mais elevadas que as máximas de verão.

Ora, os dados então disponíveis, referentes a 1983, indicavam ser esse um ano de altas vazões, ou seja, excepcionalmente chuvoso, de tal sorte que o período de águas altas de inverno deveria ser mais pronunciado. Essa previsão confirmou-se, aliás de modo catastrófico, conforme se pode verificar na figura 5 , a qual mostra que a vazão do rio, no momento da coleta dos sedimentos de superfície de fundo estava em torno de $700 \mathrm{~m}^{3} / \mathrm{s}$, pelo segundo més consecutivo (média de maio $=766,05 \mathrm{~m}^{3} / \mathrm{s}$ ), valores comparáveis ao período de maior vazão de 1982 (Fig. 4).

Dessa forma, os sedimentos então coletados refletem as fácies de superfície de fundo do estuário já adaptadas a

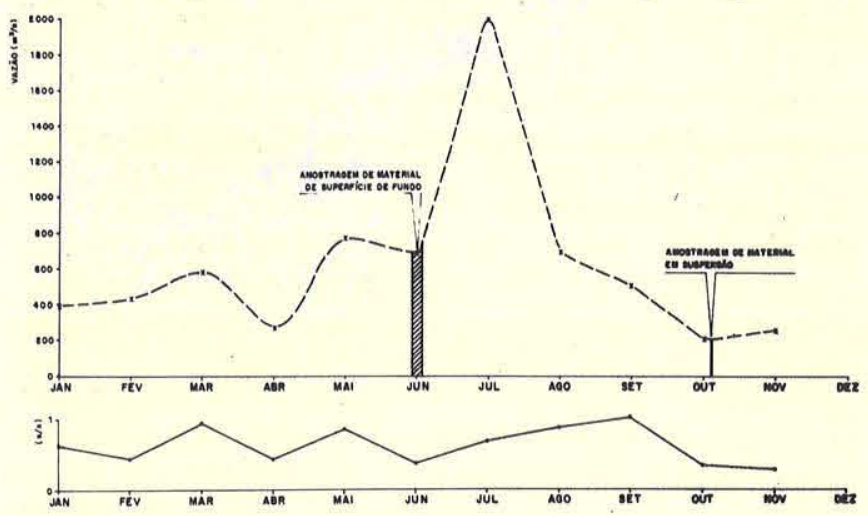

Figura 5 - Vazão do Itajai-Açu na estação de Indaial, em 1983

condições de águas altas, porém não excepcionais (que corresponderiam à situação imediatamente seguinte às cheias excepcionais do mês de julho).

Por outro lado, a coleta de água foi efetuada em 5 e 6 de outubro, ocasião em que o rio apresentava, pela curva de 1983 (Fig. 5), vazões em torno de $300 \mathrm{~m}^{3} / \mathrm{s}$. Mais precisamente, a partir de dados diários, sabe-se que a vazão do Itajaí-Açu na estação de Indaial era de $288,5 \mathrm{~m}^{3} / \mathrm{s}$ no dia 5 de outubro e de $240 \mathrm{~m}^{3} / \mathrm{s}$ no dia 6 de outubro, valores próximos dos verificados durante a campanha de 1982. Por ocasião da coleta de água, foi novamente colhido material de superfície de fundo em metade das estações do estuário.

Em síntese, em termos da vazão do rio, pode-se dizer que a campanha de 1983 se processou sob condições comparáveis às das vazões médias máximas e mínimas de 1982.

CARACTERISTICAS DOS SEDIMENTOS DE SUPERFI: CIE DE FUNDO EM 1982 . Classificação textural A distribuição faciológica (Fig. 6-A) segundo a classificação textural indica, para a área da plataforma a $\mathrm{N}$ da saída do estuário, uma gradação de areias a argilas. Estas últimas configuram uma mancha de limite grosso modo N-S. enquanto que as areias adentram o estuário contornando o molhe norte. A parte sul da porção final do estuário bem como expressiva porção da plataforma a sul de sua desembocadura são caracterizadas por siltes.

$\mathrm{O}$ restante da área estudada do estuário bem como o Saco da Fazenda, até a bacia de evolução (entornos do cais do porto), revelam uma predominância de argilas siltosas, com algumas poucas exceções.

Diâmetro médio 0 padrão obtido (Fig. 6-C) mostra uma distribuição faciológica no geral concordante com a anterior. Na região da plataforma, tem-se, da costa para $\mathbf{E}$, passagem de areias para siltes (estes com diversas gradações) sucessivamente mais finos para leste. A S do molhe norte, e adentrando o estuário até pouco após a amostra 26, tem-se uma mancha de areias finas. Esta mancha corresponde à porção final de um banco, provavelmente enriquecido com areias provenientes da zona de arrebentação próxima do molhe norte. A metade sul da porção final do estuário é dominada por sedimentos mais finos (siltes finos e siltes 

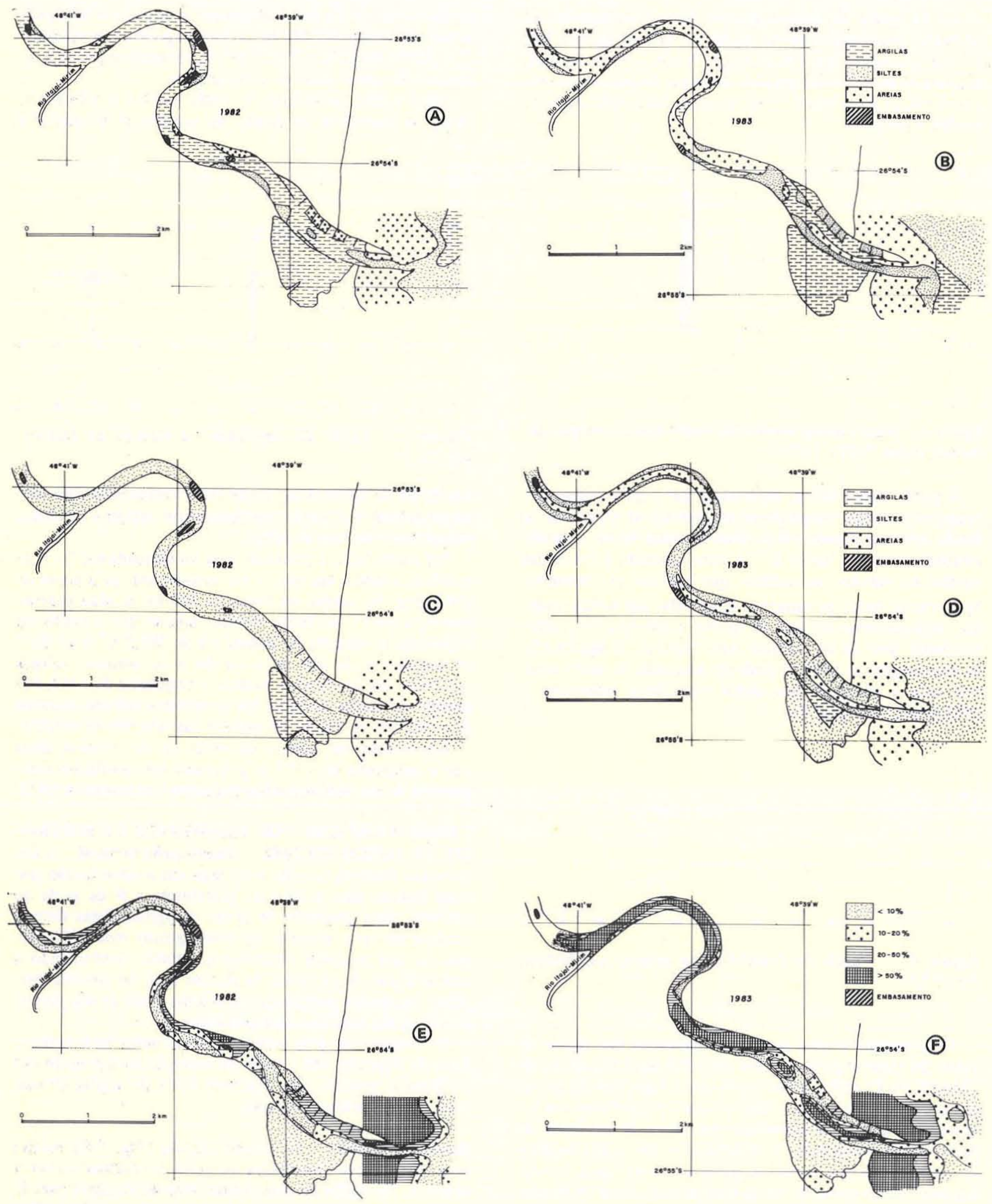

Figura 6 - Classificação textural dos sedimentos de superfície de fundo em 1982 (A) e 1983 (B); Diametros médios dos sedimentos de superfície de fundo em 1982 (C) e 1983 (D); e distribuição das porcentagens de areia dos sedimentos de superfície de fundo em 1982 (E) e 1983 (F). Localização das amostras na figura 2 
muito finos). Para o interior do estuário, até o final da bacia de evolução, dominam siltes muito finos, com algumas exceções.

\section{Distribuição das porcentagens de areia A distribuição} das classes granulométricas correspondentes às areias foi utilizada como um indicador adicional dos diferentes modos de transporte dos sedimentos no interior do estuário, pois, embora também sejam transportadas em suspensão, são predominantemente transportadas por arraste de fundo. A figura 6-E permite separar três setores distintos quanto às distribuições do material arenoso nas amostras.

O primeiro setor, situado a montante do perfil das amostras 68,69 e 70, é caracterizado por maiores quantidades de areia dispostas em faixas estreitas e alongadas localizadas nas margens convexas. Nas margens côncovas e nas porções centrais do canal, encontram-se sempre amostras com teor de material arenoso inferior a $10 \%$, sendo que em alguns locais (ponto 81, por exemplo) observou-se exposição do embasamento sedimentar mais antigo (provavelmente pré-holocênico, constituído de material silto-argiloso coeso) atestando predominância de processos erosivos.

O segundo setor coloca-se a jusante do perfil das amostras 68, 69 e 70, estendendo-se até a barra, e apresenta uma distribuição de material arenoso diversa do anterior. Aqui, embora haja uma certa tendência a concentração de material arenoso junto às margens convexas, o padrão mostra-se mais complexo evidenciando a interferência de outros processos na distribuição do material arenoso. Assim, imediatamente a jusante da bacia de evolução, que engloba as amostras 63 e 64, 60 e 61, e 56 e 58, observa-se uma área de maiores concentrações de material arenoso disposta transversalmente ao canal.

$\mathrm{Na}$ margem esquerda e rumo à barra, nas proximidades dos espigões, coloca-se uma estreita faixa de maiores concentrações de material arenoso, que se estende até a amostra 50. Mais próximo à barra e ao molhe norte (amostras 26 e 29), os teores de areia são superiores a $50 \%$ enquanto que no restante se observam concentrações de $10 \%$ a $20 \%$ e de $30 \%$ a $50 \%$.

Finalmente, o último setor, que se localiza barra afora, apresenta as maiores concentrações de material arenoso correspondentes ao domínio dos processos costeiros praiais.

Faciologia e circulação dos sedimentos de superfície de fundo em 1982 As características faciológicas dos sedimentos de superfície de fundo-descritas pela classificação textural, diâmetro médio e distribuição de porcentagens de areia-mostram limites bastante concordantes e sugestivos de diferentes modos de circulação dos sedimentos de superfície de fundo ao longo do estuário (Figs. 6-A, 6-C e 6-E).

Assim, a predominância de sedimentos siltosos na porção terminal do estuário bem como sua gradação a leste para classes sucessivamente mais finas na região da plataforma sugerem saída de material mais fino do estuário para a plataforma, onde sofreriam a ação do transporte litorâneo de sul para norte, dispondo-se em faixas paralelas à linha de costa.

Por outro lado, a presença de sedimentos arenosos em estreita faixa que perlonga o molhe norte parece indicar o avanço de água salina estuário adentro, por ocasião das preamares. Este avanço é mostrado até pouco a montante da amostra 32, através de uma faixa de areias finas e siltes grossos a médios (Figs. 6-A e 6-C).

Já as porções mais interiores do estuário mostram mo- dos distintos de transporte. Nas partes mais a montante observa-se, pela distribuição das porcentagens de areia (Fig. 6-E), uma circulação semelhante à de canais fluviais meandrantes, em que as máximas velocidades de fluxo se concentram nas margens côncovas, havendo uma diminuição de velocidade, e conseqüente deposição de material arenoso, nas margens convexas.

Mais a jusante, na área da bacia de evolução e cais principal (a jusante das amostras 68, 69 e 70), observa-se um padrão mais complexo. Neste setor, é provável que a maior concentração de material arenoso, comparativamente à porção terminal do estuário, e, ao mesmo tempo, a deposição de areias transversalmente ao canal principal sejam resultantes do barramento imposto pelas marés ao fluxo fluvial; este último teria sua velocidade reduzida ao máximo neste trecho do Itajaí-Açu.

Dessa maneira, a distribuição faciológica dos sedimentos sugere modos distintos de circulação que são con'dicionados basicamente pelo fluxo fluvial, em contraposição ao avanço das águas salinas movimentadas pelas marés, o que permite subdividir o estuário em três porções distintas no que se refere à circulação de sedimentos de superfície de fundo.

CARACTERISTICAS DOS SEDIMENTOS DE SUPERFICIE DE FUNDO EM 1983 Classificação textural Segundo este critério (Fig. 6-B), percebem-se, para a região da plataforma, dois domínios distintos, com limite N-S, grosso modo alinhados paralelamente à costa: um de areias, estendendo-se da praia até profundidades de $5-6 \mathrm{~m}$, e outro de siltes e argilas, desde a barra do estuário até a parte mais externa da área amostrada na plataforma. As areias adentram o estuário para além da amostra 45 , definindo provavelmente o limite de atuação da água marinha na movimentação de sedimentos por arraste de fundo.

A situação que se configura é de penetração de material arenoso da plataforma ao longo do molhe norte e saída de material fino do estuário em faixa ao longo do molhe sul. Este material fino une-se, na plataforma, a siltes e argilas transportados por corrente próxima da costa (que seriam, aliás, também provenientes de outros cursos d'água que chegam à costa nessa região), conforme mostram fotos aéreas e imagens de satélite.

Por outro lado, o trecho mais a montante, entre as seções 93-94-95 e 59-60-61, caracteriza-se por predomínio de fundos arenosos e acumulação de siltes e argilas especialmente nas porções de margens convexas. Esta disposição obedece já a um padrão fluvial, com domínio das condições de circulação de sedimentos pelo fluxo do rio.

Diâmetro médio Nota-se que o padrão aqui obtido (Fig. 6-D) é essencialmente semelhante ao anterior (Fig. 6-B). O alargamento da faixa arenosa na foz do Itajaí-Mirim é bastante sugestivo do aporte sólido dessa drenagem. É ainda interessante notar, no baixo estuário, que a faixa arenosa entre as seções $32-33-34$ e 44-45-46 não se acha diretamente ligada às areias da plataforma, como no caso anterior. Percebe-se ainda, com relação a 1982, aumento da área em que não se pode definir claramente qual o processo de transporte dominante, se fluvial, se marinho, que se estende entre as seções 44-45-46 e 65-66-67.

Distribuição das porcentagens de areia No geral podem-se perceber, segundo este critério (Fig. 6-F), os mesmos compartimentos definidos anteriormente. Entretanto, a distribuição das areias entre o final da bacia de evolucão 
(seção 68-69-70) e as proximidades da barra (seção 29-30-31) sugere que areias de proveniência continental possam ser transportadas mais a jusante da bacia de evolução (entornos da seção 53-54-55), eventualmente chegando à faixa arenosa que começa próximo à seção 44-45-46. Esta faixa arenosa, que estaria ligada à penetração de areias marinhas, conforme se expôs anteriormente, poderia então, em episódios de maior descarga do Itajaí-Açu, receber material arenoso continental.

Variações temporais das fácies de superfície de fundo As campanhas de amostragem de sedimentos de superfície de fundo de 1982 a 1983 referem-se a situações de descargas fluviais em torno de $250 \mathrm{~m}^{3} / \mathrm{s} \mathrm{e} 750 \mathrm{~m}^{3} / \mathrm{s}$, representativas portanto das situações médias de cheia e estiagem.

Comparando-se seus resultados pela classificação tex tural (Figs. 6-A e 6-B), temos, no que se refere à plataforma, grande semelhança de resultados com uma faixa de areias próxima à costa e uma faixa de siltes e argilas rumo ao mar, relacionada ao aporte de finos das drenagens da região, e do próprio estuário do Itajaí-Açu. Muito diversa é a situação no interior do estuário, em que, na campanha de 1982 (Fig. 6-A), tinha-se um predomínio de argilas e siltes. Em 1983 (Fig. 6-B), são as areias que predominam do início da bacia de evolução (seção 59-60-61) para montante, ocupando ainda uma expressiva área (entre a seção 44-45-46 e barra do estuário).

A distribuição de diâmetros médios em 1982 (Fig. 6-C) e em 1983 (Fig. 6-D) mostra variações semelhantes às descritas para a classificação textural.

A comparação dos mapas de distribuição das porcentagens de areia das duas campanhas mostra, mais uma vez, as mudanças ocorridas na superfície de fundo do estuário, que passa a ser revestido, durante os períodos de águas al tas, por sedimentos com altos teores de areia (Figs. 6-E e 6-F).

O limite montante da faixa mais arenosa do baixo estuário está próximo à seção 44-45-46. Por outro lado, a distribuição das porcentagens de areia na porção terminal do estuário, em 1982 (Fig. 6-E), sugeria que a influência da água marinha na penetração de material por arraste se estendia até a seção 50-51-52. Ter-se-ia então uma retração, por ocasião das águas altas de 1983 (Fig. 6-F), em cerca de $450 \mathrm{~m}$ de água salina, para jusante, quando comparada à situação de águas baixas de 1982. Levando em conta a possibilidade de transporte de areias fluviais para as porções mais baixas do estuário, deve-se considerar essa distância de $450 \mathrm{~m}$ como uma estimativa conservadora.

Adicionalmente, como foram realizadas duas amostragens de sedimentos de superfície de fundo em 1983, uma em julho e outra em outubro (Fig. 5), pôde-se comparar as situações prévia e posterior às cheias excepcionais de junho-agosto.

A distribuição de diâmetros médios em outubro de 1983 (Fig. 7) é muito semelhante à de junho de 1983 (Fig. 6-D), mostrando apenas pequeno aumento em área dos fundos arenosos.

Ressal ta-se que esta comparação é válida para a porção terminal do estuário, visto que foi amostrado em outubro metade das estações amostradas em junho e, adicionalmente, a última amostragem de 1983 (outubro) realizou-se dois meses após a fase principal das cheias, e três meses após a cheia principal. Levando em conta essas restrições, podemos considerar que a maior alteração das fácies de fundo se deu de

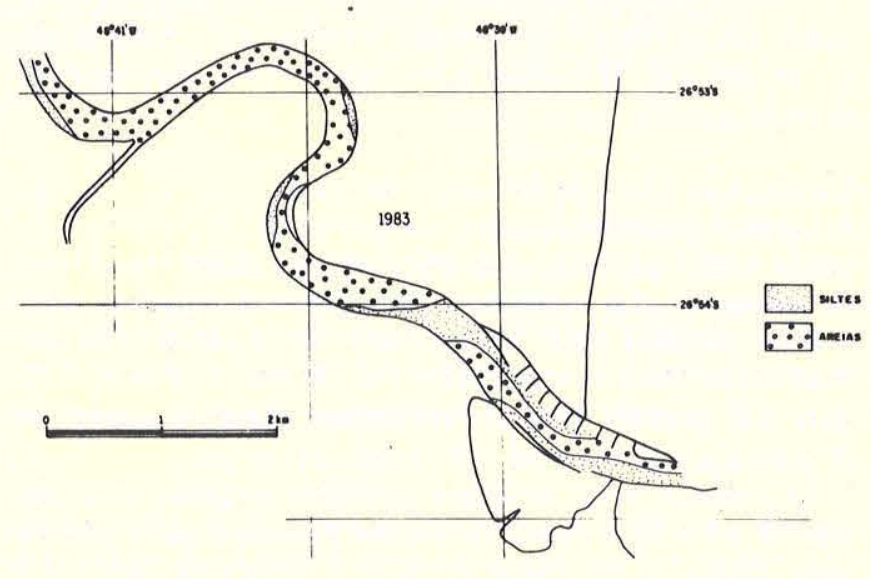

Figura 7 - Diâmetros médios dos sedimentos de superfície de fundo após a cheia catastrófica de 1983

1982 para 1983, em função das prolongadas altas vazões do rio (exceto abril, sempre acima de $400 \mathrm{~m}^{3} / \mathrm{s}$ ). Um episódio de cheia catastrófica (média máxima em julho superior a $2.000 \mathrm{~m}^{3} / \mathrm{s}$ ) não parece ter alterado substancialmente a situação prévia (junho de 1983) na distribuição das fácies dos sedimentos de superfície de fundo.

SALINIDADE E MATERIAL EM SUSPENSAO Salinidades Os valores de salinidade estão apresentados na tabela 1, e sua distribuição espacial, em curvas de isovalores, na figura 8 .

Tabela 1 - Teores de sais e concentração de materiais sólidos em suspensão em preamar e baixa-mar

\begin{tabular}{|c|c|c|c|c|c|}
\hline \multicolumn{3}{|c|}{ PREAMAR } & \multicolumn{3}{|c|}{ BAIXA-MAR } \\
\hline Amostra & $\begin{array}{c}\text { Teor em } \mathrm{NaCl} \\
\text { (ppm) }\end{array}$ & $\begin{array}{c}\text { Resíduo } \\
\text { Sólido }(\mathrm{mg} / \mathrm{l})\end{array}$ & Amostra & $\begin{array}{c}\text { Teor em } \mathrm{NaCl} \\
\text { (ppm) }\end{array}$ & $\begin{array}{c}\text { Resíduo } \\
\text { Sólido }(\mathrm{mg} / \mathrm{l})\end{array}$ \\
\hline $1 \mathrm{~T}$ & 5.600 & 33,2 & $13 \mathrm{~T}$ & 3.500 & 30,4 \\
\hline $1 \mathrm{M}$ & 25.000 & 10,9 & $13 \mathrm{M}$ & 24.000 & 31,1 \\
\hline 1B & 26.000 & 18,5 & $13 \mathrm{~B}$ & 26.000 & 60,8 \\
\hline $2 \mathrm{~T}$ & 1.500 & 27,5 & $14 \mathrm{~T}$ & 3.500 & 28,5 \\
\hline $2 \mathrm{M}$ & 26.000 & 186,4 & $14 \mathrm{M}$ & 17.000 & 30,9 \\
\hline $2 B$ & 26.000 & 267,2 & 14B & 27.000 & 226,8 \\
\hline $3 \mathrm{~T}$ & 1.300 & 27,1 & $15 \mathrm{~T}$ & 3.600 & 22,8 \\
\hline $3 \mathrm{M}$ & 30.000 & 353,2 & $15 \mathrm{M}$ & 6.000 & 30,3 \\
\hline $3 \mathrm{~B}$ & 26.000 & 108,4 & $15 B$ & 26.000 & 29,0 \\
\hline $4 \mathrm{~T}$ & 1.100 & 21,7 & $16 \mathrm{~T}$ & 3.500 & 27,9 \\
\hline $4 \mathrm{M}$ & 26.000 & 9,8 & $16 \mathrm{M}$ & 4.000 & 30,1 \\
\hline 4B & 26.000 & 80,7 & $16 \mathrm{~B}$ & 17.000 & 37,6 \\
\hline 5T & 2.500 & 29,1 & $17 \mathrm{~T}$ & 2.900 & 26,3 \\
\hline $5 \mathrm{M}$ & 26.000 & 78,8 & $17 \mathrm{M}$ & 4.200 & 19,9 \\
\hline 5B & 26.000 & 126,5 & $17 \mathrm{~B}$ & 17.000 & 15,8 \\
\hline $6 \mathrm{~T}$ & 2.400 & 24,7 & $18 \mathrm{~T}$ & 2.600 & 26,0 \\
\hline $6 \mathrm{M}$ & 25.000 & 91,5 & $18 \mathrm{M}$ & 4.000 & 26,7 \\
\hline $6 \mathrm{~B}$ & 26.000 & 215,1 & 18B & 13.000 & 24,8 \\
\hline $7 \mathrm{~T}$ & 5.000 & 29,7 & $19 \mathrm{~T}$ & 2.600 & 14,6 \\
\hline $7 \mathrm{M}$ & 24.000 & 79,5 & $19 \mathrm{M}$ & 7.000 & 34,3 \\
\hline $7 \mathrm{~B}$ & 26.000 & 233,5 & $19 \mathrm{~B}$ & 20.000 & 22,4 \\
\hline $8 \mathrm{~T}$ & 1.800 & 26,1 & $20 \mathrm{~T}$ & 2.700 & 36,6 \\
\hline $8 \mathrm{M}$ & 24.000 & 61,3 & $20 \mathrm{M}$ & 9.000 & 27,2 \\
\hline $8 \mathrm{~B}$ & 26.000 & 227,8 & $20 \mathrm{~B}$ & 25.000 & 29.7 \\
\hline 9T & 700 & 25,7 & $21 \mathrm{~T}$ & 1.800 & 35,7 \\
\hline $9 \mathrm{M}$ & 25.000 & 47,4 & $21 \mathrm{M}$ & 4.200 & 27.9 \\
\hline $9 \mathrm{~B}$ & 26.000 & 83,9 & $21 \mathrm{~B}$ & 21.000 & 17,0 \\
\hline $10 \mathrm{~T}$ & 800 & 30,8 & $22 \mathrm{~T}$ & 1.400 & 40,0 \\
\hline $10 \mathrm{M}$ & 9.000 & 16,0 & $22 \mathrm{M}$ & 2.700 & 33,6 \\
\hline $10 \mathrm{~B}$ & 25.000 & 85,6 & 22B & 20.000 & 31,2 \\
\hline $11 \mathrm{~T}$ & 300 & 36,6 & $23 \mathrm{~T}$ & 800 & 41,3 \\
\hline $11 \mathrm{M}$ & 13.000 & 13,4 & $23 \mathrm{M}$ & 14.000 & 32,8 \\
\hline $11 \mathrm{~B}$ & 25.000 & 90,5 & $23 \mathrm{~B}$ & 25.000 & 33,2 \\
\hline $12 \mathrm{~T}$ & 250 & 52,4 & $24 \mathrm{~T}$ & 1.300 & 33,5 \\
\hline $12 \mathrm{M}$ & 3.500 & 44,7 & $24 \mathrm{M}$ & 1.800 & 36,6 \\
\hline $12 \mathrm{~B}$ & 20.000 & 71,5 & $24 B$ & 2.100 & 44,0 \\
\hline
\end{tabular}




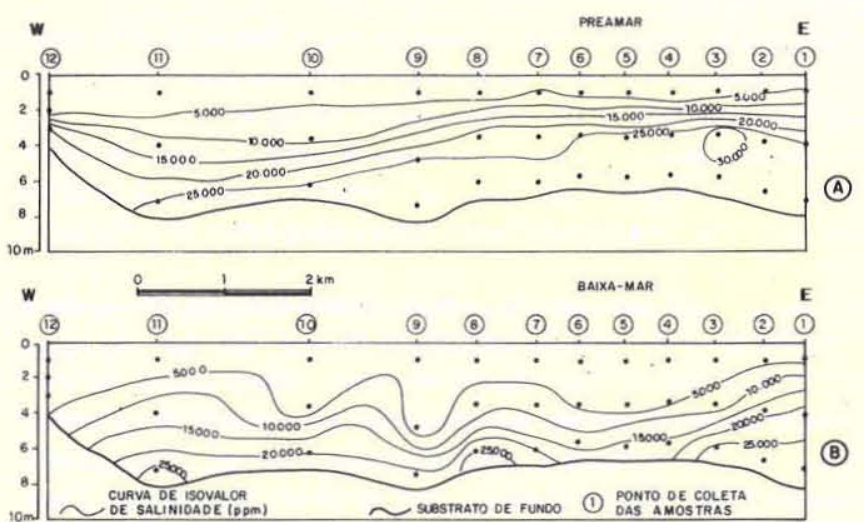

Figura 8 - Distribuição de salinidades no estuário do Itajai-Açu em: A. preamar e B. baixa-mar em 5 e 6 de outubro de 1983

A situação de preamar indica que toda a seção estudada do estuário se encontra sob domínio de águas salobras ou salgadas. Estas últimas apresentam valores mais baixos que os esperados para águas oceânicas; definem, porém, uma região de elevados teores em sais, com valores acima de $25.000 \mathrm{ppm}$, que se estende sob a forma de cunha até a estação 11.

Para a preamar, então, sob as condições de vazão investigada, próximas da vazão média do rio em estiagem, verificou-se que água marinha penetra no estuário até a estação 12 , ou seja, acima da zona máxima de influência marinha detectada pela análise dos sedimentos de superfície de fundo, sob condições semelhantes de descarga fluvial.

Em baixa-mar parece possível definir dois estratos, limitados pela curva de $5.000 \mathrm{ppm}$. Apesar de apresentar gradientes verticais de salinidade bastante similares ao longo de toda a seção, o estrato inferior mostra algumas irregularidades, basicamente porções de água mais salgada no fundo, à altura das estações 8 e 11 , além de uma nítida configuração em cunha entre as estações 1 e 4.

Material em suspensão As concentrações de sedimentos em suspensão são apresentadas na tabela 1 enquanto que sua distribuição ao longo da seção amostrada se encontra na figura 9.

A situação de preamar denota uma zona de maiores concentrações associadas à penetração da maré com intensidade máxima até as proximidades da estação 9 . O contato entre a zona de maiores e menores concentrações pode ser colocado na curva de isovalor de $100 \mathrm{mg} / \mathrm{l}$ e configura uma cunha, sugestiva de contato bem definido entre dois tipos de água.

No caso da baixa-mar, há de se notar que quase todos os valores se distribuem em faixas abaixo da última curva de isovalor de preamar (de $40 \mathrm{mg} / 1$ ). A amostra 2B foi excluída deste tratamento por apresentar valor anômalo. A partir da curva de isovalor de $45 \mathrm{mg} / 1$, situada na desembocadura do estuário (estação 1), têm-se concentrações gradativamente menores até $20 \mathrm{mg} / 1$, até pouco a montante da estação 9. Entre as estações 9 e 12 há um ligeiro aumento nas concentrações, caracterizado pela curva de $35 \mathrm{mg} / 1$. A disposição das faixas de baixa-mar é sugestiva de mistura na vertical, de parte das águas do estuário.

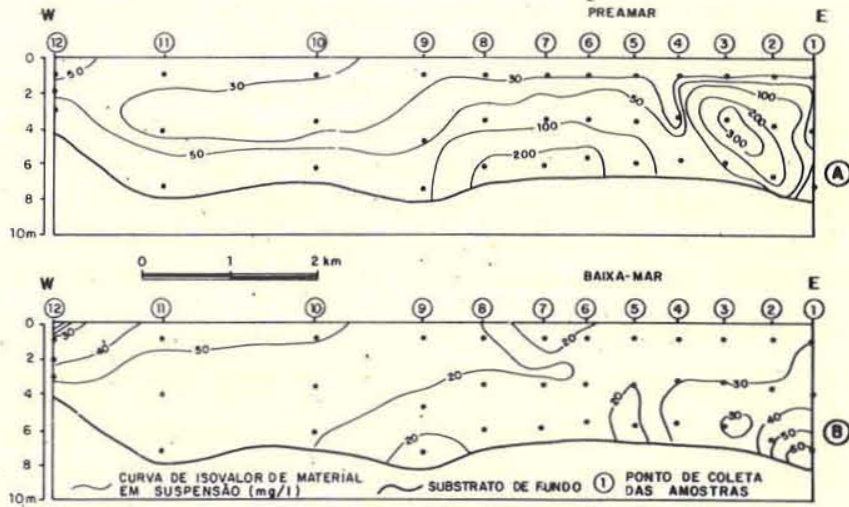

Figura 9 - Distribuição de sedimentos em suspensão no estuário de Itajai-Açu, em: A. preamar e B. baixa-mar, em 5 e 6 de outubro de 1983

Há pois um grande contraste entre as situações de preamar e baixa-mar. No primeiro caso há uma separação bem definida entre duas zonas diferentes quanto a seus teores em sedimentos em suspensão enquanto que no segundo caso não há limites nítidos a destacar.

Complementarmente, os dados da caracterização granulométrica dos sedimentos em suspensão, obtidos pelo Coulter Counter, foram analisados pelo método de Ward (Bourochev \& Saporta 1982), critério de agrupamento que consiste em fundir as duas classes mais próximas tendo como distância entre elas a perda de inércia em que se incorre ao agrupá-las. A inércia interclasse é definida como a média dos quadrados das distâncias entre os centros de gravidade de cada classe e o centro de gravidade total.

No caso da preamar, foram estabelecidos três grupos, considerados significativos em função da distribuição de valores característicos (eigenvalue) e de desvios-padrões. A seção amostrada foi então dividida em áreas de predominância de cada um dos grupos (Fig. 10-A). 0 resultado obtido é muito sugestivo da existência de uma população de sedimentos característicos da desembocadura do estuário (Grupo 2), de uma população característica de montante (Grupo 1) e de uma população intermediária entre essas duas (Grupo 3).

A distribuição dessas populações pode ser interpretada a partir da penetração de uma cunha salina: à frente do material transportado por arraste, ter-se-ia a seleção de duas populações (as dos grupos 2 e 3 ) de sedimentos colocados em suspensão, segundo o modelo de Sengupta $(1975,1979)$ e Ghosh et al. (1981). A terceira população (a do Grupo 1) poderia resultar tanto de uma diferenciação das populações anteriores como receber, em sua formação, sedimentos diferenciados a partir de transporte mais caracteristicamente fluvial.

No caso da baixa-mar, usando-se procedimento similar ao acima mencionado, pode-se notar que há uma população característica próxima ao leito do estuário (dada pelo Grupo 1) e duas outras acima desta (Fig. 10-B).

Neste caso, o limite entre as populações caracterizadas pelos grupos 2 e 3 não é nítido, o que pode permitir outras interpretações.

Essas situações são bastante sugestivas, segundo o cri- 

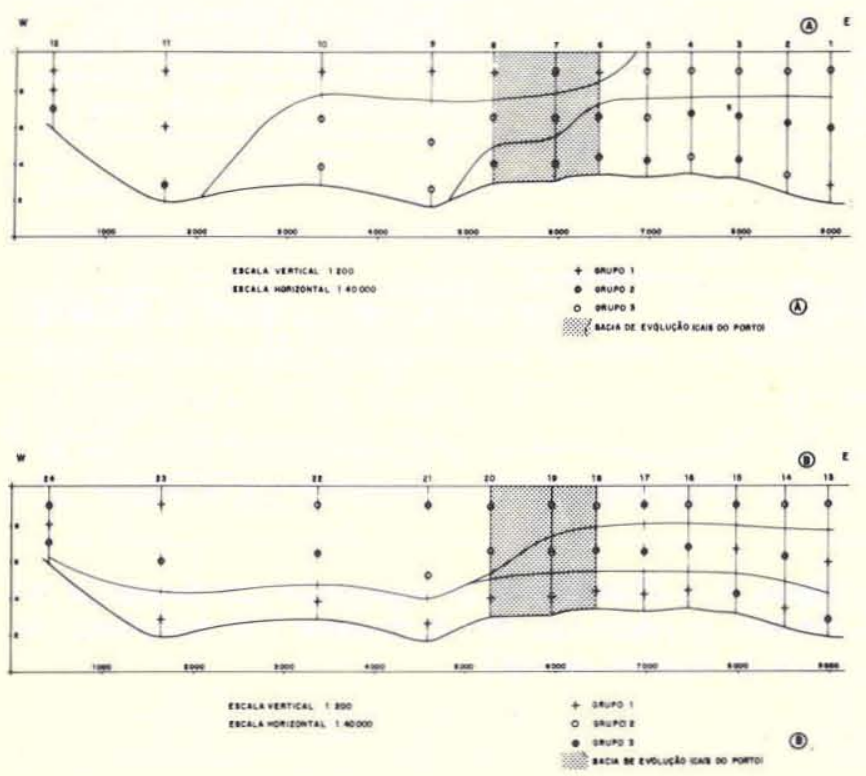

Figura 10 - Distribuição dos sedimentos em suspensão segundo grupos obtidos pelo método de Ward, para: A. preamar e B. baixa-mar

tério ora empregado, de um comportamento assimilável à penetração de uma cunha salina na preamar e de uma estratificação bastante marcada na baixa-mar, seguramente em duas faixas (talvez três) de materiais distintos em suspensão.

Circulação estuarina Não se dișpõe de medidas de velocidade de correntes no interior do estuário. Entretanto, parece que a distribuição de salinidade e alguns elementos da análise dos sólidos em suspensão permitem propor uma classificação tentativa do estuário do Itajaí-Açu.

Consideremos inicialmente a situação da salinidade na preamar (Fig. 8-A). Temos uma estratificação bem marcada, na qual se podem reconhecer grosso modo três gradientes verticais de salinidades: 1 . na porção basal, entre as estações 1 e 11, com pequenas variações de salinidade, todas iguais ou maiores que $25.000 \mathrm{ppm} ; 2$. nas profundidades intermediárias de toda a seção levantada, exceto a estação 12 , com salinidades de 5.000 a 25.000 ppm; na verdade, este gradiente é acentuado entre as estações 1 e 9 e diminui para montante; e 3. na lâmina superior do estuário, com salinidades inferiores a $5.000 \mathrm{ppm}$.

Essa distribuição de salinidades não se enquadra a rigor em nenhum dos tipos básicos apresentados por Bowden (1967), pois apresenta conformação similar a um caso de cunha salina, embora haja uma certa mistura entre águas doce e salgada.

Levando em conta que essa distribuição de salinidades representa uma situação de baixa descarga fluvial, acredita-se que o estuário em preamar, sob condições de mais alta descarga, passe a apresentar maior separação entre águas doce e salgada, aproximando-se mais tipicamente, então, do modelo de cunha salina.

$\mathrm{Na}$ baixa-mar (Fig. 8-B) podem-se reconhecer basica- mente dois estratos: um inferior, entre 5.000 e 25.000 ppm, e outro superior, com salinidades menores que $5.000 \mathrm{ppm}$, sendo o contato entre ambos muito irregular.

Neste caso, o padrão aproxima-se mais do tipo de estuário estratificado, com mistura vertical, embora possamos ainda reconhecer uma cunha mais salina entre as estações 1 e 4.

Assim, no caso do Itajaí-Açu, temos um estuário onde a circulação sofre grande influência fluvial, em que, na maré enchente, assiste ao avanço de uma cunha salina; as correntes de maré devem ser importantes a ponto de provocar uma relativa mistura de água marinha e fluvial, descaracterizando então de certa forma esse modelo. $\mathrm{Na}$ vazante à medida que recua a cunha, vai-se implantando ao longo do estuário uma circulação em dois estratos, com maior mistura das águas que na enchente, provavelmente devido a correntes de maré mais velozes.

Nesse sentido, embora o material em suspensão não seja comumente considerado elemento classificatório, traz evidências que vêm de encontro ao esquema acima proposto. Assim, na preamar pudemos notar uma distribuição de diferentes populações, compatível com a cunha salina (Fig. 10-A) e com os dois estratos (Fig. 10-B) na baixa-mar.

Esses dados, e mais a distribuição de sólidos em suspensão (Fig. 9), mostram a zona de turbidez máxima entre as estações 1 e 9 na preamar, e entre as estações 1 e 3 na baixa-mar. Assim, a zona de maior turbidez está associada à posição da cunha salina. Adicionalmente, podemos notar que os maiores teores absolutos de sólidos em suspensão se associam à água salgada e não à fluvial.

CONCLUSÕES O estuário do Itajaí-Açu é caracterizado por um regime bastante variável, que, de maneira geral, apresenta dois máximos e dois mínimos anuais de descarga fluvial. As måiores vazões fluviais ocorrem de julho a outubro e as menores de dezembro a maio; entretanto os desvios-padrões das médias mensais calculadas mostram que a uma certa regularidade sazonal se impõem episódios de grande descargas sobretudo no mês de agosto.

Sedimentos de superfície de fundo foram coletados em duas campanhas principais que correspondem a situações signiticativas de descarga fluvial. Os resultados obtidos pela análise de material sedimentar de fundo mostraram que, durante o período de águas baixas (vazões em torno de 250 $\mathrm{m}^{3} / \mathrm{s}$ ), sedimentos silto-argilosos predominavam em praticamente todo o estuário enquanto que apenas nas porções mais a montante se depositavam areias.

Por outro lado, durante o período de águas altas (vazões em torno de $750 \mathrm{~m}^{3} / \mathrm{s}$ ), constatou-se predomínio de sedimentos arenosos de aporte continental, que se estendem até a área do início dos molhes, já no baixo estuário.

A última etapa da amostragem de fundo, realizada três meses após a cheia principal, não mostrou mudanças significativas nas fácies de fundo estabelecidas durante o regime de águas altas.

A análise dos dados referentes ao material em suspensão e à distribuição de salinidades permite estabelecer o tipo de circulação estuarina, que pode variar de cunha salina a bem estratificado, dependendo das condições de maré e descarga do rio. 


\section{REFERÊNCIAS BIBLIOGRÁFICAS}

BOUROCHEV, J.M. \& SAPORTA, G. - 1982 - Análise de dados. Rio de Janeiro, Zahar Ed. 116 p.

BOWDEN, K.F. - 1967 - Circulation and diffusion. In: LAUFF, G.H. ed. Estuaries. Washington, American Association for the Advancement of Science. p. 15-36 (Publication 83)

FOLK, R.L. \& WARD, W.C. - 1957 - Brazos Riber bar: a study in significance of grain size parameters. J. Sed. Petrol., 27(1):3-26.

GHOSH, J.K.; MAZUMDER, B.S.; SENGUPTA, S. - 1981 Methods for computation of suspended load from bed materials. Sedimentology, 28:781-791.

KUTNER, A.S. - 1976 - Levantamentos sedimentológicos de apoio na pesquisa e reconhecimento de áreas portuárias. In: CONGR BRAS. GEOL. ENG., 1, Rio de Janeiro, 1976. Anais..., Rio de Janeiro, ABGE. v. 2, p. 47-66.

MARTIN, L. \& SUGUIO, K. - 1986 - Excursion route along the coastal plains of the States of Paraná and Santa Catarina. In INT. SYMP. on SEA LEVEL CHANGES and QUATERNARY SHORELINES, São Paulo, 1986 (Special Publication 1).

NIMER, E. - 1977 - Clima. In: FUNDAÇ ÃO INSTITUTO BRASILEIRO de GEOGRAFIA e ESTATÍSTICA. Geografia do Brasil, Região Sul. Rio de Janeiro, SERGRAF. v. 5, p. 75-79.

PONC, ANO, W.L. - 1976 - Sedimentação atual na baía de Sepetiba, Estado do Rio de Janeiro: contribuição à avaliação de viabilidade geotécnica da implantação de um porto. São Paulo, 2 v. (Dissertação de Mestrado/IGUSP).

PORTOBRẢS - 1979 - Plano Diretor Portuario do Brasil. s-L-

SENGUPTA, S. - 1975 - Size-sorting during suspension transportation, lognormality and other characteristics. Sedimentology, $22: 257-273$.
SENGUPTA, S. - 1979 - Grain-size arstributions of suspended load in relation to bed materials and flow velocity. Sedimentology, $26: 63-82$

SILVESTER, R. - 1968 - Sediment transport, long-term net movement. In: FAIRBRIDGE, R.W. ed. Encyclopedia of Geomorfology. London, Reinhold. p. 985-988.

SILVESTER, R. - 1974 - Coastal engineering. Amsterd am, Elsevier. 2 v. (Developments in Geothecnical Engineering 4B).

SUGUIO, K. - 1973 - Introdução à sedimentologia. São Paulo, Blücher.

SWIFT, D.J.P.; SCUBEL, J.R.; SHELDON, R.W. - 1972 - Size analyses of fine-grained suspended sediments: a review. $J$. Sed. Petrol., 42(1):122-134.

VARGAS, B.M. - 1983 - Evolução histórico-morfológica do estuário do Rio Itajai-Açu e sua implicação no Porto de Itajai-Açu. Rio de Janeiro, Portobrás/INPH. (Relatório 900/01-139/83).

WALKER, P.H.; WOODYER, K.D.; HUTKA, J. - 1974 - Particlesize measurements by coulter counter of very small deposits and low suspended sediment concentration in streams. J. Sed. Petrol., 44(3):673-679.
MANUSCRITO 378

Recebido em 29 de agosto de 1986 Revisão aceita em 29 de novembro de 1986

...É preciso, de fato, em Paris, tomar precauções infinitas para não se ver a Torre;... ela é literal como um fenômeno da natureza, da qual se pode indagar infinitamente o sentido mas não contestar a existência. 